Article

\title{
Design and Optimization of the Dual-Channel Closed Loop Supply Chain with E-Commerce
}

\author{
Essam Kaoud ${ }^{1,2, *(1)}$, Mohammad A. M. Abdel-Aal ${ }^{3}{ }^{(\mathbb{D}}$, Tatsuhiko Sakaguchi ${ }^{4}$ and Naoki Uchiyama ${ }^{1}$ \\ 1 Department of Mechanical Engineering, Toyohashi University of Technology, Toyohashi 441-8580, Japan; \\ uchiyama@tut.jp \\ 2 Mechanical Engineering Department, Faculty of Engineering, Assiut University, Assiut 71516, Egypt \\ 3 Systems Engineering Department, King Fahd University of Petroleum and Minerals, \\ Dhahran 31261, Saudi Arabia; mabdelaal@kfupm.edu.sa \\ 4 Department of Informatics, Faculty of Engineering, Kindai University, Higashi-Hiroshima 739-2116, Japan; \\ sakaguchi@hiro.kindai.ac.jp \\ * Correspondence: essam.kaoud.mohammed.mouhran.wn@tut.jp; Tel.: +81-080-6706-9467
}

Received: 10 October 2020; Accepted: 27 November 2020; Published: 3 December 2020

\begin{abstract}
The depletion of natural resources and the degradation of the ecosystem have led many countries to adopt closed-loop supply activities in both their industrial and service sectors. With the widespread use of Internet technology, these aspects motivate the incorporation of e-commerce with the classical closed-loop supply chain. This study suggests a novel mixed-integer linear programming (MILP) model that addresses the integration of e-commerce with a multi-echelon closed-loop supply chain with a multi-period planning time horizon by considering dual channels in manufacturing, and recovery facilities. To validate the model, we obtain optimal decision variables and examine the robustness and applicability of the model, and comprehensive computational experiments are performed. Moreover, sensitivity analysis is carried out to illustrate the efficacy of e-commerce integration by considering the two channels in the closed-loop supply chain. Accordingly, the total cost of the dual-channel CLSC decreases with an increase in customer demand via online retailers, the returned end of life (EOL) products, recycling ratio, and recovery ratio. Some useful managerial implications are provided based on the conducted analysis.
\end{abstract}

Keywords: mixed-integer linear programming; closed-loop supply chain; dual channel; e-commerce

\section{Introduction}

In recent years, governments have been applying pressure and refining legislation to encourage organizations and a broad sector of customers to adopt green and sustainable practices in their production and service activities. This is to handle the population growth, which requires more products to be manufactured, resulting in the limited availability of raw materials and an increase in the rate of pollution emissions [1,2]. These factors are motivating companies and governments to adopt and implement rational closed-loop supply chain (CLSC) activities in both the production and service sectors [3,4]. A CLSC incorporates both forward and reverse supply chain activities [5-7]. The forward supply chain is defined as a network involving raw material procurement, manufacturing of parts, assembly of parts, and delivery through distribution networks [8]. Meanwhile, the reverse supply chain is defined as a network of facilities and includes all activities from collecting end of life (EOL) products to their inspection, disassembly, and the determination of which components should be disposed of, recovered, recycled, and remanufactured to 
form final products that can be reused by customers [9-11]. The European Union and European Parliament came up with several changes to the Directive 2002/96/EC on Waste Electrical and Electronic Equipment (WEEE) with the objective of improved human health [12]. Many companies adhere to this legislation, and the recycling of WEEE has led to a myriad of environmental and economic benefits due to the recovery of valuable metals and plastics in these pieces of equipment [13]. Implementing CLSC planning strategies helps in reducing companies' production costs, eliminating environmental pollution, creating social gains, and promoting the rapid development of economic benefits by applying reverse logistics to the company's activities including recycling, recovering, and remanufacturing of disused products [14]. For instance, Fuji Xerox saves around 40-65\% of production costs from the manufacturing of recycled materials [15] . The rise of the Internet and related technologies has led many companies to sell their products through online retailers in addition to traditional retailers. For example, Dell sells its electronic products through online retailers such as Amazon, Flipkart, and Snapdeal [16]. Both types of retailer sell the same basic product and determine their respective optimal retail prices. In acting as the market leader, the producer has to split the market share between online and traditional retailers and decide on the wholesale price [17]. A myriad of benefits have boosted the spread of online retailers, including high accessibility, fast responses to consumer demand, low distribution costs, and fast shipping [18] as well as the positive impact from an environmental perspective $[19,20]$. The practice of combining online shopping with the traditional retail channel in the supply chain design has emerged recently. However, a limited number of studies have addressed the optimal design of a dual-channel supply chain network, Yadav and Singh [21] proposed multiple channel distribution for a forward supply chain network using MILP, their proposed model is a single-period single-product multi-channel forward supply chain with the aim to maximize the service level and minimize the total cost. Chen et al. [22] proposed a mixed integer nonlinear programming (MINLP) for modeling the remanufacturing network for the dual-channel CLSC. The authors investigated the proposed mathematical model while computational experiments and sensitivity analysis for model validity were not preformed. Motivated by this, we investigate the design and optimization of the CLSC with the dual-channel supply chain considering e-commerce in mathematical modeling. Specifically, we present a novel MILP model of the CLSC with the consideration of the dual channel of the traditional and online retailers in both forward and reverse logistics, which aims at minimizing the total cost of shipment, purchasing, operations, and fixed costs. The main contributions of this study are as follows:

- the integration of e-commerce activities into both forward and reverse supply chains;

- the development of an MILP model that considers the dual channel of both traditional and online retailers through manufacturing and recovery facilities;

- a sensitivity analysis study of the key parameters associated with traditional and online retailers, and exploring their effect on the total cost and number of open traditional retailers.

The remainder of the paper is organized as follows: Section 2 presents a literature review of the previous studies pertaining to the design and optimization of supply chains networks, Section 3 provides a description of the on-hand problem, handling the strategic and tactical design of the proposed dual-channel CLSC, Section 4 shows the mathematical formulation of the dual-channel CLSC, Section 5 discusses the computational experiments performed on the proposed model, and Section 6 concludes the paper.

\section{Literature Review}

Many researchers have traditionally investigated the design of forward and reverse supply chains as two separate issues [23]. On the one side, studies on the design of the forward supply chain include the design of a multi-echelon forward supply chain by Memari et al. [24], who developed an MILP using a metaheuristic algorithm, named a modified firefly algorithm, and verified the efficiency of their suggested algorithm, as compared with traditional ones. Designing a two-echelon, multi-commodity, 
and single period supply chain considering tactical and strategic planning to minimize the total cost of the network was proposed by Sadjady and Davoudpour [25] using a Lagrangian approach. Eskandarpour et al. [26] proposed a heuristic algorithm to maximize the material flow in a four-layer, multi-product, and single-period supply chain network.

On the flip side, studies on the design of the reverse supply chain include a three-stage mathematical programming model developed by Pochampally and Gupta [27], involving methods such as linear integer programming and multi-criteria decision-making approaches for the strategic planning of a reverse supply chain network. Alshamsi and Diabat [28] proposed a genetic algorithm and used general algebraic modeling system (GAMS) software to solve the reverse logistics problem, with the aim of determining the optimum location and capacities of inspection and remanufacturing centers. An MILP was developed by Paydar and Olfati [29] for designing and solving a reserve logistics network of polyethylene terephthalate bottles using the two metaheuristic techniques of the genetic algorithm and the imperialist competitive algorithm. Demirel et al. [30] proposed an MILP model for the reverse logistics of end of life vehicles in Turkey, with the objective of minimizing the cost of the associated activities of the supply chain network, such as transportation, recovery, and opening facilities, via income from the remanufacturable and recyclable parts of these vehicles.

The design of a closed loop supply chain is a concern that has gained a significant amount of academic attention in recent years. Özceylan and Paksoy [31] developed an MILP for a multi-period multi-part CLSC. Their study aimed at determining the optimum number of facilities as well as the location of manufacturers and retailers using a CPLEX optimizer. System dynamic simulation of the CLSC model was proposed by Golroudbary and Zahraee [32] to assess the behavior of an electrical manufacturing company. Due to the rapid e-commerce deployment, the dual channel of both traditional stores and online retailers strongly participates in supply chain network planning. Ma et al. [33] studied how government subsidies affect the dual-channel CLSC. Dutta et al. [34] provided a multi-objective optimization network model for green reverse logistic supply chains to the Indian e-commerce market to optimize supply chain costs.

A pricing strategy refers to the strategy developed by sellers when determining their market pricing, while channel coordination is defined as the setting of manufacturer's and retailer's decisions leading to channel profit maximization $[35,36]$. Exploring pricing and coordination decisions in dual-channel CLSCs with different power structures considering the channel competition between direct and retail channels was proposed by Zheng et al. [37].

Taleizadeh et al. [38] explored the impact of marketing efforts on optimal decisions and economic benefits in the CLSC using Stackelberg game theory. Their study suggested a substantial impact of the two-part tariff contract on channel coordination.

Xiao et al. [39] implemented a trade-in policy in both traditional retail channel models and dual-channel models. He et al. [40] studied the effect of a dual-channel CLSC on carbon emissions considering the free riding behavior that customers enjoy thanks to traditional retailer services; nevertheless, final purchases were made through online retailers. They verified that free riding increases carbon emissions, despite the increasing dual-channel CLSC profits.

Zhu et al. [41] examined the impact of customer bargaining behavior on dual-channel CLSC under centralized decision-making, decentralized decision-making, and contract coordination using the Stackelberg game theory. Saha et al. [42] investigated a reward-driven remanufacturing policy for dual channel closed loop supply chain coordination using game theory (GT) approach. Hong et al. [43] investigated three hybrid dual-channel collection structures and indicated that the strategic alliance between the manufacturer and the retailer can effectively achieve the desired channel coordination. Xie et al. [44] combined revenue sharing and support programs using a Stackelberg game to investigate the contract coordination mechanism. Their proposed contract increases the profits of supply chain network. 
Yuan et al. [45] presented an optimization analysis and GT approach to analyze the necessary conditions for achieving coordination interests under equilibrium conditions for manufacturers, retailers, and third-party online recyclers. Stackelberg game models were formulated by Wan and Hong [46] to analyze the optimal pricing and recycling policies for the CLSC with a retailer and dual collection channel to develop a coordination contract that would eliminate the channel conflict, resulting in an optimal retail price, optimal wholesale price, optimal collection rates, and optimal transfer prices. Wang et al. [47] studied the dual-channel CLSC with product customization through direct retail channels. Three pricing models were presented to analyze the optimal decisions of supply chain members using game theory. He et al. [48] studied the dual-channel CLSC with government subsidies to investigate the channel structure and pricing decisions for the manufacturer and the government's subsidy policy with new, competing, remanufactured products. The above-discussed literature review shows that almost all studies are concerned with pricing strategies and channel coordination, as indicated in Table 1 . To the best of our knowledge, the study presented in this paper is the first to propose an MILP for the dual channel of the CLSC with the focus of making both tactical and strategic decisions that are crucial for the development of the supply chain in the future, according to [49]. This study enriches the literature and covers some of the gaps, as shown in Table 1, by considering the traditional and online retailers that are supplied by the products from the manufacturer in the forward supply chain and the recovery products from the reverse supply chain.

Table 1. Related literature.

\begin{tabular}{cccccccc}
\hline \multicolumn{9}{c}{ Retail Channel } & \multicolumn{5}{c}{ Study Point of View } \\
\hline References & $\begin{array}{c}\text { Traditional } \\
\text { Retailer }\end{array}$ & $\begin{array}{c}\text { Online } \\
\text { Retailer }\end{array}$ & $\begin{array}{c}\text { Pricing } \\
\text { Strategy }\end{array}$ & $\begin{array}{c}\text { Channel } \\
\text { Coordination }\end{array}$ & $\begin{array}{c}\text { Tactical } \\
\text { Planning }\end{array}$ & $\begin{array}{c}\text { Strategic } \\
\text { Planning }\end{array}$ & $\begin{array}{c}\text { Modeling } \\
\text { Approach }\end{array}$ \\
\hline $\begin{array}{c}\text { Özceylan and Paksoy [31] } \\
\text { Xiao et al. [39] }\end{array}$ & $\checkmark$ & & & & $\checkmark$ & $\checkmark$ & MILP \\
Taleizadeh et al. [38] & $\checkmark$ & $\checkmark$ & & $\checkmark$ & & & GT \\
Zheng et al. [37] & $\checkmark$ & $\checkmark$ & $\checkmark$ & $\checkmark$ & & & GT \\
Zhu et al. [41] & $\checkmark$ & $\checkmark$ & $\checkmark$ & $\checkmark$ & & & GT \\
Saha et al. [42] & $\checkmark$ & $\checkmark$ & & $\checkmark$ & & & GT \\
Hong et al. [43] & $\checkmark$ & $\checkmark$ & & $\checkmark$ & & & GT \\
Xie et al. [44] & $\checkmark$ & $\checkmark$ & & $\checkmark$ & & & GT \\
Yuan et al. [45] & $\checkmark$ & $\checkmark$ & & $\checkmark$ & & & GT \\
Wan and Hong [46] & $\checkmark$ & $\checkmark$ & $\checkmark$ & & & & GT \\
Wang et al. [47] & $\checkmark$ & $\checkmark$ & $\checkmark$ & & & & GT \\
He et al. [48] & $\checkmark$ & $\checkmark$ & $\checkmark$ & & & & GT \\
Chen et al. [22] & $\checkmark$ & $\checkmark$ & & & $\checkmark$ & $\checkmark$ & MINLP \\
This study & $\checkmark$ & $\checkmark$ & & & $\checkmark$ & \\
\hline
\end{tabular}

\section{Problem Description}

The dual-channel CLSC is a multi-echelon multi-period supply chain that consists of two parts, as shown in Figure 1, the forward supply chain, which is connected by black solid arrows, and the reverse supply chain, which is connected by red dashed arrows. The suppliers and recycling centers provide the manufacturers with the raw materials, and the manufacturer then produces the final products that are transported to either traditional retailers or online retailers. Both online and traditional retailers provide the final products to the end customers of new products to satisfy their demands. Dismantlers collect the EOL products for reverse logistics in the dual channel and then decide whether to dispose of, recycle, or recover those collected EOL products. The potential locations of the facilities and distances between these locations are predefined and known. The capacities of facilities and demands of customers are predetermined and deterministic. The shipment cost, purchasing cost, operating costs, such as 
manufacturing, collecting, disposing, recycling, and recovering, and fixed costs are predetermined and fixed. The rates of online demands in the forward and reverse chain are predefined and deterministic. The ratio of EOL products to be collected and inspected is predefined and deterministic. The ratios of the disposed, recycled, and recovered products are predetermined and deterministic.

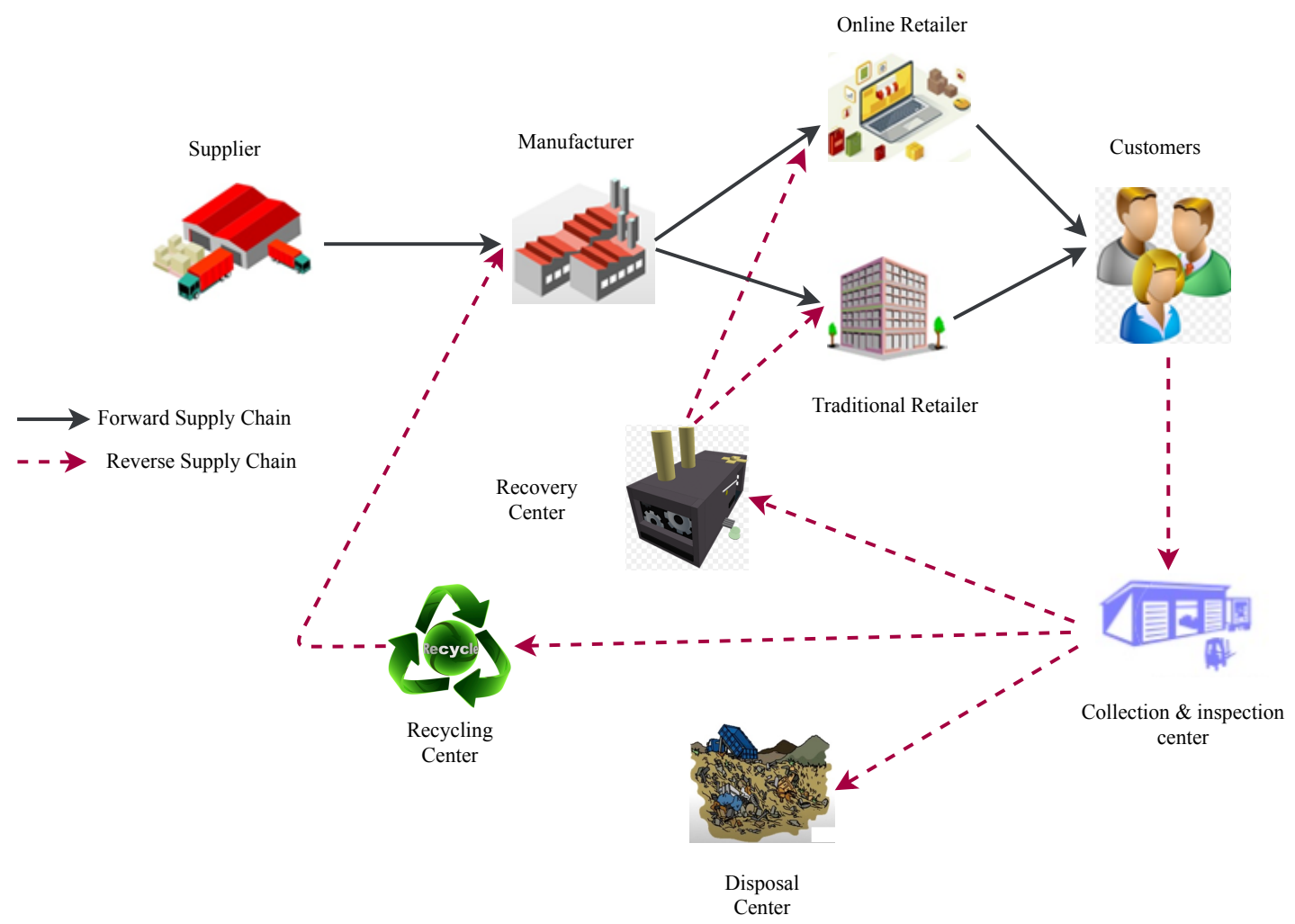

Figure 1. The proposed dual-channel closed loop supply chain (CLSC).

The model proposed in this paper determines the optimal amounts to be manufactured from the raw materials provided by the suppliers and the recycled materials supplied by recycling centers, the optimal amounts transported to both traditional and online retailers via the manufacturers or recovery centers, the optimal amounts transported to customers to satisfy their demand, the optimal number of EOL products to be collected and inspected, the disposed amounts, the optimal amounts to be recycled, and the amounts to be recovered. Additionally, the model determines the optimal number of facilities for operating the dual-channel CLSC over the planning horizon. Various parameter uncertainties were determined by applying sensitivity analysis to examine the effects of the parameters on the performance of the dual-channel CLSC to provide managerial insights for the decision-makers.

\section{Mathematical Formulation}

In this section, an MILP model for the dual-channel CLSC with e-commerce is proposed. Our proposed model is an extension of the traditional models of CLSC [31,50] in that it incorporates e-commerce activities. The objective function shown in Equation (1), composed of four parts, represents the total cost that is to be minimized. The first part of the objective function, $z_{1}$, is the transportation cost between each successive set of facilities in the CLSC during the total periods of time, represented by Equation (2). 
The second part, $z_{2}$, is the cost of the set of manufacturers purchasing raw materials from suppliers and is represented by Equation (3). The third part, $z_{3}$, is the cost of the operations, which includes manufacturing, collecting, inspection, disposal, recycling, and recovery, and is represented by Equation (4). The last part, $z_{4}$, represents the fixed costs of opening facilities in the CLSC and is represented by Equation (5). The nomenclature that is used in the mathematical formulation of the dual-channel CLSC is presented in Table 2, including the indices, parameters, and the continuous and integer decision variables.

Table 2. Nomenclature.

\begin{tabular}{|c|c|}
\hline \multicolumn{2}{|c|}{ Indices \& Sets } \\
\hline$i$ & Set of suppliers. \\
\hline$j$ & Set of manufacturers. \\
\hline$k^{t r}$ & Set of traditional retailers. \\
\hline$k^{o n}$ & Set of online retailers. \\
\hline$l$ & Set of customers. \\
\hline$m$ & Set of collection and inspection centers. \\
\hline$n$ & Set of recycling centers. \\
\hline$v$ & Set of recovery centers. \\
\hline$s$ & Set of disposal centers. \\
\hline$t$ & set of time periods. \\
\hline \multicolumn{2}{|c|}{ Parameters } \\
\hline$S C_{i j}$ & Shipment cost of the quantity transported between supplier $i$ and manufacturer $j$. \\
\hline$S C_{j k}^{t r}$ & $\begin{array}{l}\text { Shipment cost of the quantity transported between manufacturer } \mathrm{j} \text { and traditional } \\
\text { retailer } k^{t r} \text {. }\end{array}$ \\
\hline$S C_{j k}^{o n}$ & $\begin{array}{l}\text { Shipment cost of the quantity transported between manufacturer } \mathrm{j} \text { and online } \\
\text { retailer } k^{o n} \text {. }\end{array}$ \\
\hline$S C_{k^{t r} l}$ & $\begin{array}{l}\text { Shipment cost of the quantity transported between traditional retailers } k^{t r} \text { and } \\
\text { customer } l \text {. }\end{array}$ \\
\hline$D C_{k^{o n} l}$ & $\begin{array}{l}\text { Delivery cost of the quantity transported between online retailers } k^{o n} \text { and } \\
\text { customer } l \text {. }\end{array}$ \\
\hline$S C_{l m}$ & $\begin{array}{l}\text { Shipment cost of the quantity transported between customer } l \text { and } \\
\text { collection center } m \text {. }\end{array}$ \\
\hline$S C_{m s}$ & $\begin{array}{l}\text { Shipment cost of the quantity transported between collection center } m \text { and disposal } \\
\text { center } s \text {. }\end{array}$ \\
\hline$S C_{m v}$ & $\begin{array}{l}\text { Shipment cost of the quantity transported between collection center } m \text { and recovery } \\
\text { center } v \text {. }\end{array}$ \\
\hline$S C_{n j}$ & $\begin{array}{l}\text { Shipment cost of the quantity transported between recycling center } n \text { and } \\
\text { manufacturer } j \text {. }\end{array}$ \\
\hline$S C_{v k^{o n}}$ & $\begin{array}{l}\text { Shipment cost of the quantity transported between recovery center } v \text { and online } \\
\text { retailer } k^{o n} \text {. }\end{array}$ \\
\hline$C a_{\zeta t}$ & $\begin{array}{l}\text { The capacity of the CLSC facilities belongs to } \zeta \text { in period } t \text { where } \\
\zeta:\left\{i, j, k^{t r}, k^{o n}, l, m, s, n, v .\right\}\end{array}$ \\
\hline$D e_{l t}$ & Demand of customer $l$ in period of time $t$. \\
\hline$P C$ & $\begin{array}{l}\text { Purchasing cost of the unit of product transported between supplier } i \\
\text { and manufacturer } j \text {. }\end{array}$ \\
\hline jc & Manufacturing cost of a product. \\
\hline$m c$ & Collection and inspection cost of an EOL product. \\
\hline sic & Disposing cost of an EOL product. \\
\hline$y c$ & Recycling cost of an EOL product. \\
\hline$v c$ & Recovery cost of an EOL product. \\
\hline$F C_{i t}$ & Fixed cost associated with selected supplier $i$ in period $t$. \\
\hline$F C_{j t}$ & Fixed cost of opening manufacturer $j$ in period $t$. \\
\hline
\end{tabular}


Table 2. Cont.

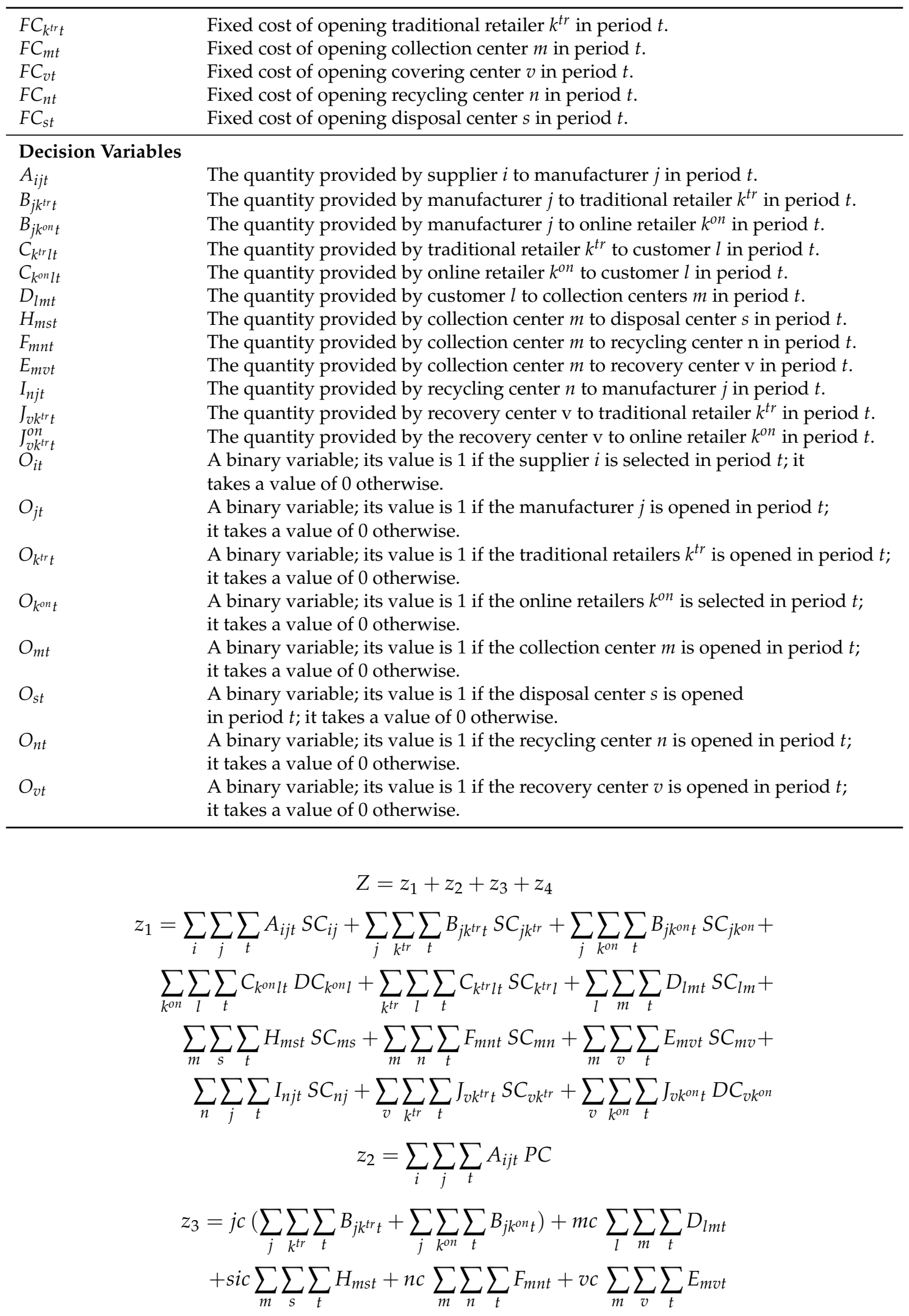




$$
\begin{array}{r}
z_{4}=\sum_{i} \sum_{t} F C_{i t} O_{i t}+\sum_{j} \sum_{t} F C_{j t} O_{j t}+\sum_{k^{t r}} \sum_{t} F C_{k^{t r} t} O_{k^{t r} t}+\sum_{m} \sum_{t} F C_{m t} O_{m t}+ \\
\sum_{s} \sum_{t} F C_{s t} O_{s t}+\sum_{n} \sum_{t} F C_{n} O_{n t}+\sum_{v} \sum_{t} F C_{v t} O_{v t}
\end{array}
$$

The model is subject to a set of constraints expressed in the following relations: the capacity constraint of the suppliers described by Equation (6): the quantity transported from each supplier to all the manufacturers during each period must not surpass the capacity of that supplier.

$$
\sum_{j} A_{i j t} \leq C a_{i t} O_{i t} \forall i, t
$$

Constraints described by Equation (7) present the capacity of the manufacturer such that the quantity transported from any manufacturer to the set of forward traditional and online retailers must not exceed the capacity of that manufacturer during any period of the planning horizon.

$$
\sum_{k^{t r}} B_{j k^{t r} t}+\sum_{k^{o n}} B_{j k^{o n} t} \leq C a_{j t} O_{j t} \forall j, t
$$

Constraints described by Equations (8) and (9) address the capacities of traditional and online retailers and ensure that the quantity transported to the customers should not exceed the capacity of each retailer during any period of the planning horizon.

$$
\begin{gathered}
\sum_{l} C_{k^{t r} l t} \leq C a_{k^{t r} t} O_{k^{t r} t} \forall k^{t r}, t \\
\sum_{l} C_{k^{o n} l t} \leq C a_{k^{o n_{t}}} O_{k^{o n_{t}}} \forall k^{o n}, t
\end{gathered}
$$

Constraints described by Equation (10) guarantee the satisfaction of the customer's demand over the planning horizon.

$$
\sum_{k^{t r}} C_{k^{t r l} l t}+\sum_{k^{o n}} C_{k^{o n} l t} \geq D e_{l t} \quad \forall l, t
$$

Constraints represented by Equation (11) identify the capacity of the collection and inspection centers and make sure that the amounts transferred to the disposal, recycling, and recovery centers will not exceed those centers' capacities at any time of the planning horizon.

$$
\sum_{s} H_{m s t}+\sum_{n} F_{m n t}+\sum_{v} E_{m v t} \leq C a_{m t} O_{m t} \forall m, t
$$

Constraints on the capacity of disposal centers described by Equation (12) ensure that the quantity transported to the disposal centers from the collection and inspection centers do not exceed their capacities at any period of the planning horizon.

$$
\sum_{m} H_{m s t} \leq C a_{s t} O_{s t} \forall s, t
$$

The Constraints described by Equation (13) identify the capacity of the recycling centers and guarantee that the quantities transported to the manufacturers from the recycling centers do not exceed their capacities at any period of the planning horizon.

$$
\sum_{j} I_{n j t} \leq C a_{n t} O_{n t} \forall n, t
$$


The constraints described by Equation (14) present the limitations on the capacity of the recovery centers and ensure that the quantities transported to both the traditional and online retailers do not exceed the capacity of those centers at any period of the planning horizon.

$$
\sum_{k^{t r}} J_{v k^{t r} t}+\sum_{k^{o n}} J_{v k^{o n} t} \leq C a_{v t} O_{v t} \forall v, t
$$

Moreover, the equilibrium constraints of the facilities of the dual-channel CLSC show that the amounts produced by the manufacturers, which are supplied by the suppliers and recycling centers, are divided between the traditional retailers and the online retailers as described by Equations (15) and (16).

$$
\begin{gathered}
\lambda\left(\sum_{i} A_{i j t}+\sum_{n} I_{n j t}\right)-\sum_{k^{t r}} B_{j k^{t r t}}=0 \quad \forall j, t \\
(1-\lambda)\left(\sum_{i} A_{i j t}+\sum_{n} I_{n j t}\right)-\sum_{k^{o n}} B_{j k^{o n} t}=0 \quad \forall j, t
\end{gathered}
$$

Another set of equilibrium constraints on the traditional retailers assures that the quantity transported from the manufacturers and recovery centers to a traditional retailer is equal to the quantity transported from these retailers to the customers as described by Equation (17).

$$
\sum_{j} B_{j k^{t r} t}+\sum_{v} J_{v k^{t r} t}-\sum_{l} C_{k^{t r l} l t}=0 \forall k^{t r}, t
$$

Another set of equilibrium constraints on the online retailers is considered to make sure that the quantity transported from the manufacturers and recovery centers to this retailer is equal to the quantity transported from this retailer to the customers as described by Equation (18).

$$
\sum_{j} B_{j k^{o n_{t}}}+\sum_{v} J_{v k^{o n_{t}}}-\sum_{l} C_{k^{o n l t}}=0 \forall k^{o n}, t
$$

Equilibrium constraints on the demands of the customers show that the quantity provided by the customer is equal to a certain amount that is a proportion of End of Life products (EOL), $\mu$, that is transported to the collection and inspection centers as described by Equation (19).

$$
\mu\left(\sum_{k^{t r}} C_{k^{t r} l t}+\sum_{k^{o n}} C_{k^{o n} l t}\right)-\sum_{m} D_{l m t}=0 \quad \forall l, t
$$

The equilibrium constraints on the collection and inspection centers show that the quantity of the EOL product transported to these centers are distributed in proportions of the $\pi, \rho$, and $\tau$ of these products that are disposed, recycled, and recovered, respectively, as described by Equations (20)-(23).

$$
\begin{aligned}
& \sum_{s} H_{m s t}-\pi \sum_{l} D_{l m t}=0 \quad \forall m, t \\
& \sum_{n} F_{m n t}-\rho \sum_{l} D_{l m t}=0 \quad \forall m, t \\
& \sum_{v} E_{m v t}-\tau \sum_{l} D_{l m t}=0 \quad \forall m, t
\end{aligned}
$$

where

$$
\pi+\rho+\tau=1
$$


Equilibrium constraints on the amount transported to the manufacturers from the recycling centers such that it equals the amount transported from the collection and inspection centers to these centers as described by Equation (24).

$$
\sum_{m} F_{m n t}-\sum_{j} I_{n j t}=0 \forall n, t
$$

Equilibrium constraints of the recovery centers, such that a proportion $\phi$ of the recovered products is transported to the traditional retailers, and the remainder of the recovered products is transported to the online retailers, described by Equations (25) and (26).

$$
\begin{gathered}
\phi \sum_{m} E_{m v t}-\sum_{k^{t r}} J_{v k^{t r} t}=0 \forall v, t \\
(1-\phi) \sum_{m} E_{m v t}-\sum_{k^{o n}} J_{v k^{o n} t}=0 \quad \forall v, t
\end{gathered}
$$

Finally, non-negativity and integrity constraints for the decision variable as described by Equations (27) and (28).

$$
\begin{gathered}
A_{i j t}, B_{j k^{t r} t}, B_{j k^{o n} t}, C_{k^{t r} l t}, C_{k^{o n l} l t}, D_{l m t}, H_{m s t}, F_{m n t}, E_{m v t}, I_{n j t}, J_{v k^{t r} t}, J_{v k^{o n} t} \geq 0 \\
O_{\Omega t}=\left\{\begin{array}{ccc}
1 & \text { if the facility } \Omega \text { opens in period } t \\
0 & \text { otherwise } & \text { forall } \Omega:\left\{i, j, k^{t r}, k^{o n}, m, s, n, v\right\}
\end{array}\right.
\end{gathered}
$$

\section{Computational Experiments}

In this section, numerical experiments were performed using the GAMS-CPLEX 12.9 solver to validate the dual-channel CLSC using a personal computer (Intel Core i7, 3 GHz CPU, RAM 16 GB, Windows 10 OS). The proposed mathematical model is composed of 389 decision variables (317 continuous and 72 binary variables) and 200 constraints. It is well known that the complexity of the dual-channel CLSC problem is NP-hard because of number of binary variables. The computational requirements are proportional with the number of binary variables [51,52] of the dual-channel CLSC, which are $O_{i t}, O_{j t}, O_{k^{t r} t}, O_{k^{n_{t}}}, O_{m t}$, $O_{s t}, O_{n t}$, and $O_{v t}$ and equal to $\left|i+j+k^{t r}+k^{o n}+m+s+n+v\right| *|t|$ in the studied problem. Small size instances are used in this paper for model validation. NP-hard problems are validated by implementing the small size instances using the exact solution obtained by GAMS software $[25,53]$.

\subsection{Description of the Data}

The dual-channel CLSC proposed in this study, which is depicted in Figure 1, is a single product. Multiple echelons and four time periods are composed of four suppliers, two manufacturers, two traditional retailers, two online retailers, and three customer sets. Moreover, the facilities in the reverse chain are composed of two collection and inspection centers, two disposal centers, two recycling centers and two recovery centers. Some of the data implemented in this study are taken from a study presented by Mohammed et al. [50], shown in Table 3. 
Table 3. The model's parameter values.

\begin{tabular}{cc}
\hline Parameters & Values \\
\hline$F C_{i t}$ & uniform $(5,000,10,000)$ \\
$F C_{j t}$ & uniform $(30,000,60,000)$ \\
$F C_{m t}$ & uniform $(2500,5000)$ \\
$F C_{n t}$ & uniform $(20,000,30,000)$ \\
$F C_{s t}$ & uniform $(4000,5000)$ \\
$F C_{k^{t r} t}$ & uniform $(10,000,12,000)$ \\
$F C_{v t}$ & uniform $(10,000,30,000)$ \\
$P C$ & uniform $(11,13)$ \\
$j c$ & uniform $(21,24)$ \\
$m c$ & uniform $(6,9)$ \\
$s i c$ & uniform $(7,9)$ \\
$y c$ & uniform $(2,4)$ \\
$v c$ & uniform $(10,15)$ \\
\hline
\end{tabular}

The distances among the different facilities in kilometers are presented in Table A3. The shipment cost of a product is estimated as 0.08 USD per $\mathrm{km}$, and the delivery cost of a product requested from the online retailers is 1.0 USD per product. The capacities of the dual-channel CLSC facilities are presented in Table A1, and the customer demand is presented in Table A2.

A fraction of the customers demand $(\lambda=0.70)$ of products is supplied by traditional retailers, while the remainder of the demand is supplied by online retailers. The fraction of the EOL products $(\mu=0.70)$ is transported to the collection centers, a fraction of the collected and inspected products $(\rho=0.30)$ is recycled, and another fraction of these products $(\tau=0.30)$ is recovered, and the remainder $(\pi=0.40)$ of these products is disposed. The fraction of the recovered products $(\phi=0.70)$ is transported to the traditional retailers, while the remainder of these products is transported to the online retailers. Strategic and tactical decisions are obtained, and sensitivity analysis of dual-channel CLSC parameter changes that are beneficial from managerial perspectives is considered.

\subsection{Results}

Strategic and tactical decision variables for the dual-channel CLSC were obtained, and the optimal flow between facilities and the optimal opening and closure times of facilities are determined as presented in Table 4. Manufacturers are provided by the raw material through suppliers and recycling centers, and these manufacturers cooperate with recovery centers to provide the products for traditional and online retailers. The total cost of the dual-channel CLSC is 1,165,352 USD, of which $19 \%$ is transportation costs, $5 \%$ is purchasing costs, $18 \%$ is operation costs, and the remainder is the fixed costs. 
Table 4. Strategic and tactical decisions for the dual-channel CLSC.

\begin{tabular}{|c|c|c|c|c|c|}
\hline Decision Variables & From/To & $t_{1}$ & $t_{2}$ & $t_{3}$ & $t_{4}$ \\
\hline \multirow[t]{2}{*}{$A_{i j t}$} & supplier 2-manufacturer 4 & 1108 & 1102 & 0 & 0 \\
\hline & supplier 4-manufacturer 3 & 0 & 0 & 1026 & 0 \\
\hline \multirow{5}{*}{$B_{j k^{t r} t}$} & manufacturer 1-traditional retailer 1 & 281 & 279 & 0 & 279 \\
\hline & manufacturer 3-traditional retailer 1 & 0 & 0 & 760 & 0 \\
\hline & manufacturer 3-traditional retailer 2 & 0 & 0 & 219 & 0 \\
\hline & manufacturer 4-traditional retailer 1 & 775 & 771 & 0 & 441 \\
\hline & manufacturer 4-traditional retailer 2 & 0 & 0 & 0 & 330 \\
\hline \multirow{3}{*}{$B_{j k^{o n} t}$} & manufacturer 1 -online retailer 1 & 120 & 120 & 0 & 120 \\
\hline & manufacturer 3-online retailer 2 & 0 & 0 & 420 & 0 \\
\hline & manufacturer 4 -online retailer 1 & 332 & 331 & 0 & 331 \\
\hline \multirow{4}{*}{$C_{k^{t r} l t}$} & traditional retailer 1 -customer 1 & 550 & 550 & 540 & 540 \\
\hline & traditional retailer 1 -customer 2 & 620 & 600 & 391 & 320 \\
\hline & traditional retailer 1 -customer 3 & 167 & 180 & 89 & 140 \\
\hline & traditional retailer 2-customer 2 & 0 & 0 & 219 & 330 \\
\hline \multirow{2}{*}{$C_{k^{o n} l t}$} & online retailer 1 -customer 3 & 538 & 570 & 111 & 570 \\
\hline & online retailer 2-customer 3 & 35 & 0 & 419 & 0 \\
\hline \multirow{4}{*}{$D_{l m t}$} & customer 1 -collection center 1 & 0 & 385 & 378 & 378 \\
\hline & customer 1 -collection center 2 & 385 & 0 & 0 & 0 \\
\hline & customer 2 -collection center 1 & 434 & 420 & 427 & 455 \\
\hline & customer 3 -collection center 1 & 518 & 525 & 434 & 497 \\
\hline \multirow[t]{2}{*}{$H_{m s t}$} & collection center 1 -disposal center 2 & 381 & 532 & 496 & 532 \\
\hline & collection center 2 -disposal center 1 & 154 & 0 & 0 & 0 \\
\hline \multirow[t]{2}{*}{$E_{m v t}$} & collection center 1 -recovery center 1 & 285 & 399 & 372 & 399 \\
\hline & collection center 2-recovery center 2 & 116 & 0 & 0 & 0 \\
\hline \multirow[t]{2}{*}{$I_{n j t}$} & recycling center 1 -manufacturer 1 & 401 & 399 & 0 & 399 \\
\hline & recycling center 2-manufacturer 3 & 0 & 0 & 372 & 0 \\
\hline \multirow{3}{*}{$F_{m n t}$} & collection center 1-recycling center1 & 286 & 399 & 0 & 399 \\
\hline & collection center 1 -recycling center 2 & 0 & 0 & 372 & 0 \\
\hline & collection center 2 -recycling center 1 & 116 & 0 & 0 & 0 \\
\hline \multirow[t]{2}{*}{$J_{v k^{t r} t}$} & recovery center 1 -traditional retailer 1 & 200 & 279 & 260 & 279 \\
\hline & recovery center 2 -traditional retailer 1 & 81 & 0 & 0 & 0 \\
\hline \multirow[t]{2}{*}{$J_{v k^{o n} t}$} & recovery center 1 -online retailer 1 & 86 & 120 & 111 & 120 \\
\hline & recovery center 2 -online retailer 2 & 35 & 0 & 0 & 0 \\
\hline
\end{tabular}

\subsection{Sensitivity Analysis of the Dual-Channel CLSC Parameters}

This section provides a comprehensive sensitivity analysis of the dual-channel CLSC parameters and their effect on the overall cost. The experimental computation manipulates four scenarios of parameter sensitivity analysis and their impact on the total supply chain cost. The baseline scenario is the current situation as presented in the previous section for all such analyses in this section using the same approach implemented in the literature [54-56]. A crucial question that the baseline can address relates to knowing that the model is valid [57]. The first scenario considers customer demand variations. The second scenario investigates the variations in the quantity produced by the manufacturer directed at both traditional and online retailers. For example, e-commerce retail grows six-fold in the US from 2000 to 2009 [58]. The third scenario handles the change in the proportions of EOL products returned for 
recycling, disposal, and recovery, and their effect on the dual-channel CLSC. The last scenario considers an adjustment in the inspection ratios of items for recycling, disposal, and recovery.

\subsubsection{Customer Demand Ratio Change from Traditional Retailers}

Due to the advantages of e-commerce and the availability of the Internet, customer demand through online retailers has increased dramatically, and competition from traditional retailers has decreased. This study proposes changing the fraction of the products supplied to traditional retailers due to the change in the fraction of products supplied to online retailers. Therefore, the number of opening times of traditional retailers has been decreased over the planning horizon due to the increase in the online retailer demand ratio, as shown in Figure 2. Additionally, the effect of the ratios of manufactured and recovered products directed to traditional retailers on the dual-channel CLSC cost is presented in Table 5.

Table 5. The impact of the ratios of manufactured and recovered products for traditional retailers on the dual-channel CLSC's cost.

\begin{tabular}{ccccccc}
\hline$\lambda, \boldsymbol{\phi}$ & $\begin{array}{c}\text { Transportation } \\
\text { Cost }\end{array}$ & $\begin{array}{c}\text { Purchasing } \\
\text { Cost }\end{array}$ & $\begin{array}{c}\text { Operations } \\
\text { Cost }\end{array}$ & $\begin{array}{c}\text { Fixed } \\
\text { Cost }\end{array}$ & $\begin{array}{c}\text { Total Cost } \\
\text { (USD) }\end{array}$ & $\begin{array}{c}\text { Total Cost } \\
\text { Change }\end{array}$ \\
\hline 1.0 & $241,303.4$ & $55,152.1$ & $208,792.9$ & $698,971.4$ & $1,204,219.8$ & $3.3 \%$ \\
0.9 & $235,389.3$ & $55,152.1$ & $208,792.9$ & $698,971.4$ & $1,198,305.6$ & $2.9 \%$ \\
0.8 & $229,532.8$ & $55,152.1$ & $208,792.9$ & $688,271.7$ & $1,181,749.5$ & $1.4 \%$ \\
0.7 & $223,835.5$ & $55,152.1$ & $208,792.9$ & $677,572.1$ & $1,165,352.6$ & 0 \\
0.6 & $218,269.8$ & $55,152.1$ & $208,792.9$ & $683,430.8$ & $1,165,645.6$ & $0.02 \%$ \\
0.5 & $214,189.8$ & $55,152.1$ & $208,792.9$ & $662,031.5$ & $1,140,166.3$ & $-2.2 \%$ \\
0.4 & $207,650.7$ & $55,152.1$ & $208,792.9$ & $662,031.5$ & $1,133,627.2$ & $-2.8 \%$ \\
\hline
\end{tabular}

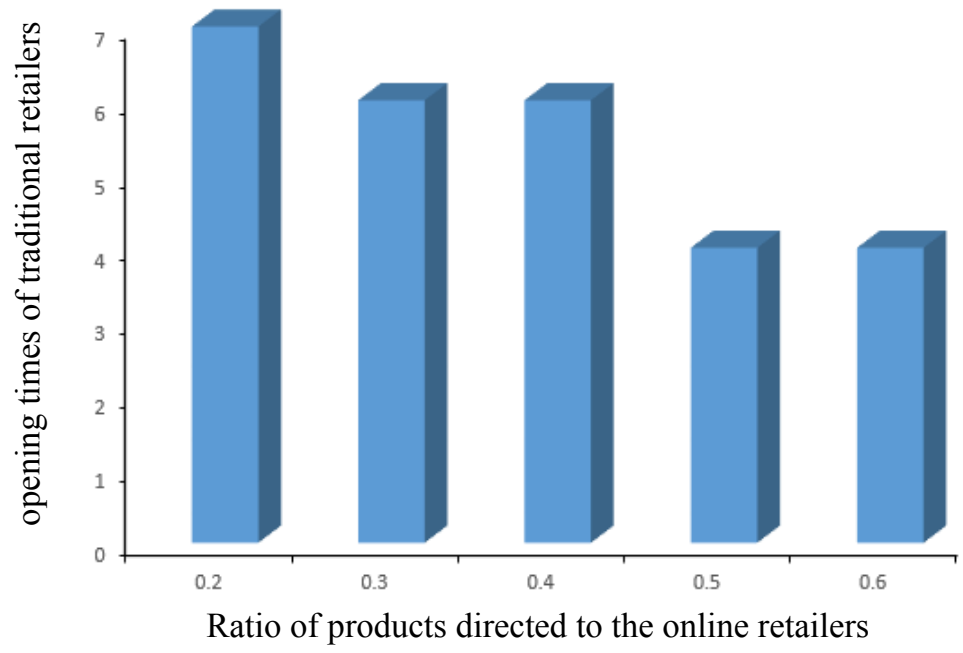

Figure 2. Influence of the demand via online retailers on the number of opening times of traditional retailers.

\subsubsection{Influence of Customers Demand Change on Dual-Channel CLSC Costs}

Sensitivity analysis of the incremental change of demand of customers $\beta$ with incremental demand between $10 \%$ and $40 \%$ was performed, and the effect on the related types of costs and the total cost of the dual-channel CLSC is presented in Table 6 . The total cost increased by $24 \%$ as a result of an increase in demand of $40 \%$. 
Table 6. The effect of customer demand on the dual-channel CLSC's cost.

\begin{tabular}{ccccccc}
\hline $\boldsymbol{\beta}$ & $\begin{array}{c}\text { Transportation } \\
\text { Cost }\end{array}$ & $\begin{array}{c}\text { Purchasing } \\
\text { Cost }\end{array}$ & $\begin{array}{c}\text { Operations } \\
\text { Cost }\end{array}$ & $\begin{array}{c}\text { Fixed } \\
\text { Cost }\end{array}$ & $\begin{array}{c}\text { Total Cost } \\
\text { (USD) }\end{array}$ & $\begin{array}{c}\text { Total Cost } \\
\text { Change }\end{array}$ \\
\hline $0 \%$ & $223,835.5$ & $55,152.1$ & $208,792.9$ & $677,572.1$ & $1,165,352.6$ & 0 \\
$10 \%$ & $239,992.9$ & $60,387.1$ & $228,611.5$ & $749,428.5$ & $1,278,420.0$ & $9.7 \%$ \\
$20 \%$ & $263,073.0$ & $66,108.8$ & $250,272.4$ & $760,128.1$ & $1,339,582.3$ & $14.9 \%$ \\
$30 \%$ & $286,139.5$ & $71,697.7$ & $271,430.8$ & $760,128.1$ & $1,389,396.2$ & $19.2 \%$ \\
$40 \%$ & $308,340.3$ & $77,212.9$ & $292,310.1$ & $771,845.6$ & $1,449,708.9$ & $24.4 \%$ \\
\hline
\end{tabular}

\subsubsection{Effect of the Proportion of EOL Products on the Dual-Channel CLSC Cost}

Recently, some companies and governments have begun to encourage the customer to return EOL products. To do so, they offer incentives or discounts on new products by changing the EOL products [59] as well as subsidies that play a crucial role in promoting the overall operational performance of the CLSC and social surplus [60].

Increasing the ratio of EOL products to the CLSC's reverse activities, such as recycling, recovery, and disposal, leads to a reduction in the CLSC's overall cost, as shown in Table 7, due to an increase in the amount of recycling and recovered products, and a decrease in the purchase of new (not recycled) raw materials as shown in Figure 3.

Table 7. Effect of the proportion of the EOL products directed to reverse logistics.

\begin{tabular}{ccccccc}
\hline $\boldsymbol{\mu}$ & $\begin{array}{c}\text { Transportation } \\
\text { Cost }\end{array}$ & $\begin{array}{c}\text { Purchasing } \\
\text { Cost }\end{array}$ & $\begin{array}{c}\text { Operations } \\
\text { Cost }\end{array}$ & $\begin{array}{c}\text { Fixed } \\
\text { Cost }\end{array}$ & $\begin{array}{c}\text { Total Cost } \\
\text { (USD) }\end{array}$ & $\begin{array}{c}\text { Total Cost } \\
\text { Change }\end{array}$ \\
\hline 0.6 & $208,339.1$ & $60,857.4$ & $201,620.5$ & $738,728.8$ & $1,209,545.9$ & $3.8 \%$ \\
0.7 & $223,835.5$ & $55,152.1$ & $208,792.9$ & $677,572.1$ & $1,165,352.6$ & 0 \\
0.8 & $245,353.0$ & $46,023.4$ & $220,268.7$ & $622,274.1$ & $1,133,919.3$ & $-2.7 \%$ \\
0.9 & $253,911.9$ & $43,741.3$ & $223,137.7$ & 566,976 & $1,087,767.1$ & $-6.6 \%$ \\
\hline
\end{tabular}

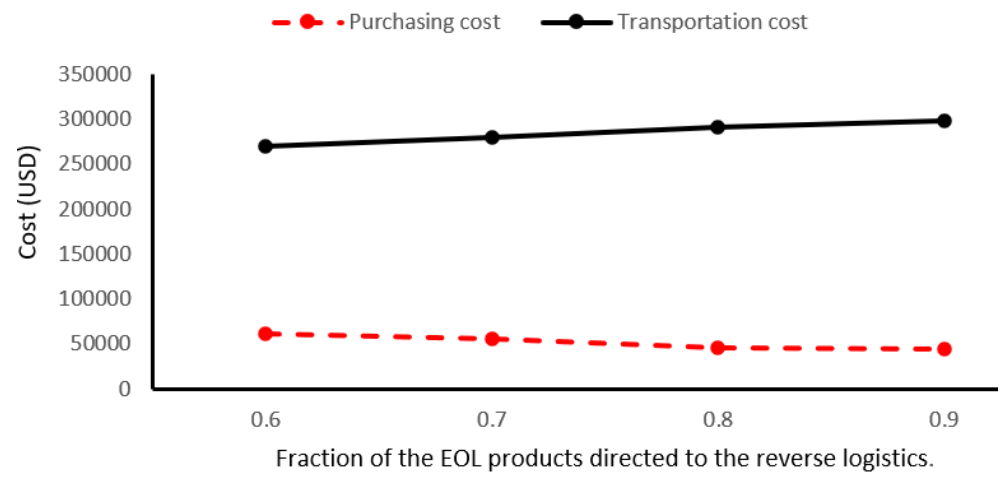

Figure 3. Impact of the ratio of EOL products on purchasing and transportation costs.

\subsubsection{Impact of Reverse Ratios of Recycling, Disposal, and Recovery on the Dual-Channel CLSC's Cost}

The ratios of the the quantities directed after collection and inspection for recycling, recovery, and disposal affect the total performance of the dual-channel CLSC. Sensitivity analysis was performed on the change in the ratios directed to disposal, recycling, and recovery centers, as shown in Table 8. 
Table 8. The change in reverse ratios of recycling, disposal, and recovery centers.

\begin{tabular}{ccccccccc}
\hline \multicolumn{7}{c}{ Reverse Ratios } & \multicolumn{7}{c}{ Dual Channel CLSC Costs } \\
\hline$\pi$ & $\boldsymbol{\rho}$ & $\boldsymbol{\tau}$ & $\begin{array}{c}\text { Transportation } \\
\text { Cost }\end{array}$ & $\begin{array}{c}\text { Purchasing } \\
\text { Cost }\end{array}$ & $\begin{array}{c}\text { Operations } \\
\text { Cost }\end{array}$ & $\begin{array}{c}\text { Fixed } \\
\text { Cost }\end{array}$ & $\begin{array}{c}\text { Total Cost } \\
\text { (USD) }\end{array}$ & $\begin{array}{c}\text { Total Cost } \\
\text { Change }\end{array}$ \\
\hline 0.2 & 0.4 & 0.4 & $228,202.4$ & $41,839.5$ & $206,926.6$ & $534,600.2$ & $1,011,568.7$ & $-13 \%$ \\
0.3 & 0.4 & 0.4 & $219,926.6$ & $48,495.8$ & $207,859.8$ & $677,572.1$ & $1,153,854.3$ & $-1.0 \%$ \\
0.4 & 0.3 & 0.3 & $223,835.5$ & $55,152.1$ & $208,792.9$ & $677,572.1$ & $1,165,352.6$ & 0.0 \\
\hline 0.4 & 0.4 & 0.3 & $223,546.9$ & $51,823.9$ & $210,321.5$ & $677,572.1$ & $1,163,264.4$ & $-0.18 \%$ \\
0.3 & 0.3 & 0.4 & $228,308.8$ & $48,495.8$ & $203,869.4$ & $534,600.2$ & $1,015,274.2$ & $-12.9 \%$ \\
0.3 & 0.3 & 0.5 & $215,228.6$ & $45,167.7$ & $197,417.4$ & $534,600.2$ & $992,413.8$ & $-14.8 \%$ \\
\hline 0.4 & 0.3 & 0.3 & $223,835.5$ & $55,152.1$ & $208,792.9$ & $677,572.1$ & $1,165,352.6$ & 0.0 \\
0.3 & 0.4 & 0.3 & $223,258.2$ & $48,495.8$ & $211,850.1$ & $677,572.1$ & $1,161,176.2$ & $-0.36 \%$ \\
0.2 & 0.5 & 0.3 & $222,681.0$ & $41,839.5$ & $214,907.3$ & $677,572.1$ & $1,156,999.9$ & $-0.72 \%$ \\
\hline
\end{tabular}

Increasing the ratio of the amount directed to disposal centers contributes to an increase in the CLSC's overall cost due to an increase in demand for the purchase of new raw material, as seen in the first portion of Table 8. Conversely, an increment in the recovery and recycling ratios of returned EOL products reduces the total cost by reducing the amount of new material purchased and increasing the number of recovered products, and this is depicted in the second and third portions of Table 8.

\subsection{Managerial Implications for the Dual-Channel CLSC}

Inspired by the numerical results and sensitivity analysis from Section 5.3, this section presents some managerial implications for the dual-channel CLSC from the prospective of manufacturers, recovery centers, and governments. Manufacturers and recovery centers are recommended to increase the ratio of products directed to online retailers by considering advertisements and promotions for online shopping. This will result in a decrease in the total cost of the dual-channel CLSC, thereby increasing the total profit due to the drastic spread of the increased volume of e-commerce. The ratio of the returned products has a major impact on the total cost of dual-channel CLSC. To increase this ratio, governments are advised to support the companies and encourage the costumers to return the EOL products. This move has large economic, social, and environmental benefits.

\section{Conclusions and Future Trends}

This study proposes an MILP model of the dual-channel CLSC to address the increasingly widespread adoption of e-commerce, facilitated by the Internet and related technologies. The adoption of e-commerce and the customer trends of online shopping for new, remanufactured, and recovered products are driven by a variety of brands and products, the comfort afforded by e-commerce, and savings of customer time and effort. From the industry and service sector perspectives, e-commerce represents increased revenue due to cost savings and reduced air pollution, resulting in a significant environmental impact benefiting health. A computational experimental using GAMS-CPLEX 12.9 is performed to obtain optimum values of strategic and decision variables and to minimize the total cost of the dual-channel CLSC. Sensitivity analysis is conducted to investigate the impact and dependency the of strategic and tactical decisions on the major key parameters of the developed model, and the robustness, validity, and applicability of the proposed model are demonstrated.

Among the key findings of the conducted computational experiments and comprehensive sensitivity analysis compared with baseline, the number of opened traditional retailers decreases with the increase in the online retailer demand ratio, accordingly, the total dual-channel CLSC decreases. 
Moreover, the total dual-channel CLSC decreases with the increase of the returned EOL products, recycling ratio, and recovery ratio.

Regarding the limitations of this study, the study does not consider the response of customers to both traditional and online retailers, the carbon emissions due to the trade-offs between traditional and online retailers are ignored, and the uncertainty in the demand in both traditional and online retailers was not taken into consideration. Future research directions may include the following:

- The uncertainty of model parameters and the environmental and social impacts can be taken into consideration in dual-channel CLSC models using stochastic optimization approaches, such as the Mulvey robust optimization approach [61], the sample average approximation method [62], and the robust optimization approach developed by Bertsimas et al. [63] and Ben-Tal et al. [64].

- To improve the efficiency of computations and the quality of solutions for large and complex dual-channel CLSC problems is mandatory, heuristics and meta-heuristics approaches can be used $[65,66]$.

- The supply chain risks (operational and disruption risks) and ripple effect on the dual-channel CLSC can be considered, and alternative plans using digital supply chain twins can be provided [67].

- Carbon and greenhouse gas emissions can be included in mathematical models to investigate their effects on model performance.

- The linkage between dual-channel CLSC and circular economy from application and theoretical points of view can be implemented.

The findings of this study are expected to be beneficial to both academics and managerial practitioners. For academicians, this study suggests new future trends, as mentioned in this section. Furthermore, this study contributes in helping managerial practitioners to realize the importance of online retailers, besides traditional ones; in addition, it motivates them to cooperate with governments in educating customers about the recycling and recovery of EOL products. This, in turn, could consolidate environmental sustainability.

Author Contributions: Conceptualization, E.K., T.S., and M.A.M.A.-A.; modeling, E.K. and M.A.M.A.-A.; methodology, E.K. and M.A.M.A.-A.; supervision, T.S. and N.U.; revision E.K., M.A.M.A.-A., T.S., and N.U.; writing - original draft, E.K. All authors have read and agreed to the published version of the manuscript.

Funding: This research received no external funding.

Acknowledgments: The authors acknowledge the Japanese Ministry of Education, Culture, Sports, Science and Technology (MEXT: Monbu-kagaku-shō) for their support during this study. Also, we would like to thank the anonymous referees for their constructive comments.

Conflicts of Interest: The authors declare that there is no conflict of interest.

\author{
Abbreviations \\ The following abbreviations are used in this manuscript: \\ MILP Mixed Integer linear Programming \\ GT Game theory \\ MINLP Mixed Integer Non Linear Programming \\ CLSC Closed Loop Supply Chain \\ EOL End of Life \\ e-commerce electronic commerce
}




\section{Appendix A}

Table A1. The capacities of CLSC facilities for different periods of time.

\begin{tabular}{ccccc}
\hline & $\boldsymbol{t}_{\mathbf{1}}$ & $\boldsymbol{t}_{\mathbf{2}}$ & $\boldsymbol{t}_{\mathbf{3}}$ & $\boldsymbol{t}_{\mathbf{4}}$ \\
\hline Supplier 1 & 1400 & 1440 & 1470 & 1480 \\
Supplier 2 & 1500 & 1520 & 1530 & 1540 \\
Supplier 3 & 1400 & 1410 & 1420 & 1440 \\
Supplier 4 & 1450 & 1520 & 1500 & 1530 \\
\hline Manufacturer 1 & 1250 & 1170 & 1120 & 1150 \\
Manufacturer 2 & 1240 & 1210 & 1200 & 1250 \\
Manufacturer 3 & 1400 & 1400 & 1410 & 1410 \\
Manufacturer 4 & 1200 & 1280 & 1280 & 1320 \\
\hline Traditional retailer 1 & 1900 & 1710 & 1120 & 1100 \\
Traditional retailer 2 & 1650 & 1300 & 900 & 1050 \\
\hline Online retailer 1 & 720 & 740 & 750 & 730 \\
Online retailer 2 & 900 & 920 & 810 & 840 \\
\hline Collection-center1 & 2700 & 2700 & 2700 & 2750 \\
Collection-center2 & 2680 & 2600 & 2660 & 2680 \\
\hline Disposal-center 1 & 1660 & 1660 & 1670 & 1680 \\
Disposal-center 2 & 1670 & 1670 & 1670 & 1690 \\
\hline Recycling-center1 & 1620 & 1680 & 1610 & 1790 \\
Recycling-center2 & 1600 & 1760 & 1890 & 1880 \\
\hline Recovery-center1 & 1620 & 1810 & 1700 & 1900 \\
Recovery-center2 & 1700 & 1780 & 1690 & 1800 \\
\hline
\end{tabular}

Table A2. The customers demand of products.

\begin{tabular}{ccccc}
\hline & $\boldsymbol{t}_{\mathbf{1}}$ & $\boldsymbol{t}_{\mathbf{2}}$ & $\boldsymbol{t}_{\mathbf{3}}$ & $\boldsymbol{t}_{\mathbf{4}}$ \\
\hline Customer 1 & 550 & 550 & 540 & 540 \\
Customer 2 & 620 & 600 & 610 & 650 \\
Customer 3 & 740 & 750 & 620 & 710 \\
\hline
\end{tabular}

Table A3. Distances between the dual-channel CLSC facilities (km).

\begin{tabular}{ccccc}
\hline & Manufacturer 1 & Manufacturer 2 & Manufacturer 3 & Manufacturer 4 \\
\hline Supplier 1 & 80 & 100 & 150 & 120 \\
Supplier 2 & 100 & 120 & 160 & 80 \\
Supplier 3 & 220 & 130 & 200 & 160 \\
Supplier 4 & 160 & 110 & 130 & 150 \\
\hline & Traditional retailer 1 & Traditional retailer 2 & Online retailer 1 & Online retailer 2 \\
\hline Manufacturer 1 & 100 & 115 & 80 & 110 \\
Manufacturer 2 & 110 & 120 & 90 & 100 \\
Manufacturer 3 & 90 & 100 & 100 & 80 \\
Manufacturer 4 & 80 & 80 & 120 & 130 \\
\hline
\end{tabular}


Table A3. Cont.

\begin{tabular}{|c|c|c|c|c|}
\hline & Manufacturer 1 & Manufacturer 2 & Manufacturer 3 & Manufacturer 4 \\
\hline & Customer 1 & Customer 2 & Customer 3 & \\
\hline Traditional retailer 1 & 100 & 80 & 120 & \\
\hline Traditional retailer 2 & 110 & 90 & 130 & \\
\hline Collection center 1 & 110 & 100 & 90 & \\
\hline \multirow[t]{2}{*}{ Collection center 2} & 90 & 115 & 110 & \\
\hline & Disposal center 1 & Disposal center 2 & Recycling center 1 & Recycling center 2 \\
\hline collection center 1 & 150 & 130 & 100 & 90 \\
\hline \multirow[t]{2}{*}{ collection center 2} & 160 & 170 & 90 & 120 \\
\hline & Recovery 1 & Recovery 2 & & \\
\hline Collection center 1 & 80 & 110 & & \\
\hline \multirow[t]{2}{*}{ Collection center 2} & 100 & 70 & & \\
\hline & Manufacturer 1 & Manufacturer 2 & Manufacturer 3 & Manufacturer 4 \\
\hline Recycling center 1 & 100 & 130 & 160 & 170 \\
\hline \multirow[t]{2}{*}{ Recycling center 2} & 140 & 200 & 150 & 220 \\
\hline & Traditional retailer 1 & Traditional retailer 2 & Online retailer 1 & Online retailer 2 \\
\hline Recovery center 1 & 50 & 60 & 90 & 110 \\
\hline Recovery center 2 & 60 & 80 & 110 & 100 \\
\hline
\end{tabular}

\section{References}

1. Liu, Z.; Nishi, T. Government regulations on closed-loop supply chain with evolutionarily stable strategy. Sustainability 2019, 11, 5030. [CrossRef]

2. Gupta, S.; Palsule-Desai, O.D. Sustainable supply chain management: Review and research opportunities. IIMB Manag. Rev. 2011, 23, 234-245. [CrossRef]

3. Govindan, K.; Soleimani, H. A review of reverse logistics and closed-loop supply chains: A Journal of Cleaner Production focus. J. Clean. Prod. 2017, 142, 371-384. [CrossRef]

4. Pourhejazy, P.; Kwon, O.K. A Practical Review of Green Supply Chain Management: Disciplines and Best Practices. J. Int. Logist. Trade 2016, 14, 156-164. [CrossRef]

5. Amin, S.H.; Zhang, G.; Eldali, M.N. A review of closed-loop supply chain models. J. Data Inf. Manag. 2020, 2, 279-307. [CrossRef]

6. Yildiz, T. Optimization of Logistics and Supply Chain Systems: Theory and Practice. In CreateSpace Independent Publishing Platform, Izmir, Turkey; CreateSpace Independent Publishing Platform: Scotts Valley, CA, USA, 2016.

7. Pourhejazy, P.; Kwon, O.K. The new generation of operations research methods in supply chain optimization: A review. Sustainability 2016, 8, 1033. [CrossRef]

8. Abd El-Aal, M.A.M.; El-Sharief, M.A.; El-Deen, A.E.; Nassr, A.B. Supply chain performance evaluation: A comprehensive evaluation system. Int. J. Bus. Perform. Supply Chain Model. 2011, 3, 141-166. [CrossRef]

9. Chandiran, P.; Surya Prakasa Rao, K. Design of reverse and forward supply chain network: A case study. Int. J. Logist. Syst. Manag. 2008, 4, 574-595. [CrossRef]

10. Guo, S.; Shen, B.; Choi, T.M.; Jung, S. A review on supply chain contracts in reverse logistics: Supply chain structures and channel leaderships. J. Clean. Prod. 2017, 144, 387-402. [CrossRef]

11. Paksoy, T.; Bektaş, T.; Özceylan, E. Operational and environmental performance measures in a multi-product closed-loop supply chain. Transp. Res. Part E Logist. Transp. Rev. 2011, 47, 532-546. [CrossRef]

12. Directive, E.C. Directive 2012/19/EU of the European Parliament and of the Council of 4 July 2012 on waste electrical and electronic equipment, WEEE. OJEU 2012, 197, 38-71. 
13. Baxter, J.; Lyng, K.A.; Askham, C.; Hanssen, O.J. High-quality collection and disposal of WEEE: Environmental impacts and resultant issues. Waste Manag. 2016, 57, 17-26. [CrossRef] [PubMed]

14. Yu, H.; Solvang, W.D. A fuzzy-stochastic multi-objective model for sustainable planning of a closed-loop supply chain considering mixed uncertainty and network flexibility. J. Clean. Prod. 2020, 266, 121702. [CrossRef]

15. Yi, P.; Huang, M.; Guo, L.; Shi, T. Dual recycling channel decision in retailer oriented closed-loop supply chain for construction machinery remanufacturing. J. Clean. Prod. 2016, 137, 1393-1405. [CrossRef]

16. Available online: https://www.mbaskool.com/marketing-mix/products/16980-dell.html (accessed on 28 November 2020).

17. Raza, S.A.; Govindaluri, S.M. Pricing strategies in a dual-channel green supply chain with cannibalization and risk aversion. Oper. Res. Perspect. 2019, 6, 100118. [CrossRef]

18. Amrouche, N.; Yan, R. A manufacturer distribution issue: How to manage an online and a traditional retailer. Ann. Oper. Res. 2016, 244, 257-294. [CrossRef]

19. Jia, D.; Li, S. Optimal decisions and distribution channel choice of closed-loop supply chain when e-retailer offers online marketplace. J. Clean. Prod. 2020, 265, 121767. [CrossRef]

20. Mohtashami, Z.; Aghsami, A.; Jolai, F. A green closed loop supply chain design using queuing system for reducing environmental impact and energy consumption. J. Clean. Prod. 2020, 242, 118452. [CrossRef]

21. Yadav, V.S.; Singh, A.R.; Jain, N. Optimization of Supply Chain Network Design for Multiple-Channel Distribution. IEOM 2018, 47, 1831-1840.

22. Chen, C.; Zhang, G.; Xia, Y. Remanufacturing Network Design for Dual-Channel Closed-Loop Supply Chain. Procedia CIRP 2019, 83, 479-484. [CrossRef]

23. Govindan, K.; Popiuc, M.N.; Diabat, A. Overview of coordination contracts within forward and reverse supply chains. J. Clean. Prod. 2013, 47, 319-334. [CrossRef]

24. Memari, A.; Ahmad, R.; Akbari Jokar, M.R.; Rahim, A.; Rahman, A. A new modified firefly algorithm for optimizing a supply chain network problem. Appl. Sci. 2019, 9, 7. [CrossRef]

25. Sadjady, H.; Davoudpour, H. Two-echelon, multi-commodity supply chain network design with mode selection, lead-times and inventory costs. Comput. Oper. Res. 2012, 39, 1345-1354. [CrossRef]

26. Eskandarpour, M.; Dejax, P.; Péton, O. A large neighborhood search heuristic for supply chain network design. Comput. Oper. Res. 2017, 80, 23-37. [CrossRef]

27. Pochampally, K.K.; Gupta, S.M. Strategic planning of a reverse supply chain network. Int. J. Integr. Supply Manag. 2005, 1, 421-441. [CrossRef]

28. Alshamsi, A.; Diabat, A. A Genetic Algorithm for Reverse Logistics network design: A case study from the GCC. J. Clean. Prod. 2017, 151, 652-669. [CrossRef]

29. Paydar, M.M.; Olfati, M. Designing and solving a reverse logistics network for polyethylene terephthalate bottles. J. Clean. Prod. 2018, 195, 605-617. [CrossRef]

30. Demirel, E.; Demirel, N.; Gökçen, H. mixed integer linear programming model to optimize reverse logistics activities of end-of-life vehicles in Turkey. J. Clean. Prod. 2016, 112, 2101-2113. [CrossRef]

31. Özceylan, E.; Paksoy, T. A mixed integer programming model for a closed-loop supply-chain network. Int. J. Prod. Res. 2013, 51, 718-734. [CrossRef]

32. Golroudbary, S.R.; Zahraee, S.M. System dynamics model for optimizing the recycling and collection of waste material in a closed-loop supply chain. Simul. Model. Pract. Theory 2015, 53, 88-102. [CrossRef]

33. Ma, W.M.; Zhao, Z.; Ke, H. Dual-channel closed-loop supply chain with government consumption-subsidy. Eur. J. Oper. Res. 2013, 226, 221-227. [CrossRef]

34. Dutta, P.; Mishra, A.; Khandelwal, S.; Katthawala, I. A multiobjective optimization model for sustainable reverse logistics in Indian E-commerce market. J. Clean. Prod. 2020, 249, 119348. [CrossRef]

35. Jeuland, A.P.; Shugan, S.M. Managing channel profits. Mark. Sci. 1983, 2, 239-272. [CrossRef]

36. Swami, S.; Shah, J. Channel coordination in green supply chain management. J. Oper. Res. Soc. 2013, 64, 336-351. [CrossRef]

37. Zheng, B.; Yang, C.; Yang, J.; Zhang, M. Dual-channel closed loop supply chains: Forward channel competition, power structures and coordination. Int. J. Prod. Res. 2017, 55, 3510-3527. [CrossRef] 
38. Taleizadeh, A.A.; Sane-Zerang, E.; Choi, T.M. The effect of marketing effort on dual-channel closed-loop supply chain systems. IEEE Trans. Syst. Man Cybern. Syst. 2016, 48, 265-276. [CrossRef]

39. Xiao, L.; Wang, X.J.; Chin, K.S. Trade-in strategies in retail channel and dual-channel closed-loop supply chain with remanufacturing. Transport. Res. E-Log. 2020, 136, 101898. [CrossRef]

40. He, R.; Xiong, Y.; Lin, Z. Carbon emissions in a dual channel closed loop supply chain: The impact of consumer free riding behavior. J. Clean. Prod. 2016, 134, 384-394. [CrossRef]

41. Zhu, X.; Wang, J.; Tang, J. Recycling pricing and coordination of WEEE dual-channel closed-loop supply chain considering consumers' bargaining. Int. J. Environ. Res. Public Health 2017, 14, 1578. [CrossRef]

42. Saha, S.; Sarmah, S.P.; Moon, I. Dual channel closed-loop supply chain coordination with a reward-driven remanufacturing policy. Int. J. Prod. Res. 2016, 54, 1503-1517. [CrossRef]

43. Hong, X.; Wang, Z.; Wang, D.; Zhang, H. Decision models of closed-loop supply chain with remanufacturing under hybrid dual-channel collection. Int. J. Adv. Manuf. Tech. 2013, 68, 1851-1865. [CrossRef]

44. Xie, J.; Zhang, W.; Liang, L.; Xia, Y.; Yin, J.; Yang, G. The revenue and cost sharing contract of pricing and servicing policies in a dual-channel closed-loop supply chain. J. Clean. Prod. 2018, 191, 361-383. [CrossRef]

45. Yuan, Y.; Yang, J.; Li, Y.; Li, W. Necessary conditions for coordination of dual-channel closed-loop supply chain. Technol. Forecast. Soc. Chang. 2020, 151, 119823. [CrossRef]

46. Wan, N.; Hong, D. The impacts of subsidy policies and transfer pricing policies on the closed-loop supply chain with dual collection channels. J. Clean. Prod. 2019, 224, 881-891. [CrossRef]

47. Wang, J.; Jiang, H.; Yu, M. Pricing decisions in a dual-channel green supply chain with product customization. J. Clean. Prod. 2020, 247, 119101. [CrossRef]

48. He, P.; He, Y.; Xu, H. Channel structure and pricing in a dual-channel closed-loop supply chain with government subsidy. Int. J. Prod. Econ. 2019, 213, 108-123. [CrossRef]

49. Stadtler, H.; Kilger, C. Supply Chain Management and Advanced Planning; Springer: Berlin/Heidelberg, Germany, 2002; Volume 4.

50. Mohammed, F.; Selim, S.Z.; Hassan, A.; Syed, M.N. Multi-period planning of closed-loop supply chain with carbon policies under uncertainty. Transp. Res. D Transp. Environ. 2017, 51, 146-172. [CrossRef]

51. Gary, M.R.; Johnson, D.S. Computers and Intractability: A Guide to the Theory of NP-completeness. In Handbook of Ripple Effects in the Supply Chain; WH Freeman and Company: New York, NY, USA, 1979.

52. Earl, M.G.; D'andrea, R. Iterative MILP methods for vehicle-control problems. IEEE Trans. Robot. 2005, 21, 1158-1167. [CrossRef]

53. Rabbani, M.; Navazi, F.; Eskandari, N.; Farrokhi-Asl, H. A green transportation location-inventory-routing problem by dynamic regional pricing. Ind. Eng. Manag. Syst. 2020, 7, 35-58.

54. Bing, X.; Bloemhof-Ruwaard, J.M.; van der Vorst, J.G. Sustainable reverse logistics network design for household plastic waste. Flex. Serv. Manuf. J. 2014, 26, 119-142. [CrossRef]

55. Bhaumik, P.K. Supply chain network design based on integration of forward and reverse logistics. Glob. Bus. Rev. 2015, 16, 680-699. [CrossRef]

56. Almeida, J.F.D.F.; Conceição, S.V.; Pinto, L.R.; de Camargo, R.S.; Júnior, G.D.M. Flexibility evaluation of Flexibility evaluation of multiechelon supply chains. PLOS ONE 2018, 13, e0194050. [CrossRef]

57. Watson, M.; Lewis, S.; Cacioppi, P.; Jayaraman, J. Supply Chain Network Design: Applying Optimization and Analytics to the Global Supply Chain; Pearson Education, Upper Saddle River, NJ, USA, 2013.

58. Kim, S.; Haghighi, F.; Eastin, M.S. Hedonic tendencies and the online consumer: An investigation of the online shopping process. J. Internet Commer. 2011, 10, 68-90. [CrossRef]

59. Taleizadeh, A.A.; Haghighi, F.; Niaki, S.T.A. Modeling and solving a sustainable closed loop supply chain problem with pricing decisions and discounts on returned products. J. Clean. Prod. 2019, 207, 163-181. [CrossRef]

60. Wang, Y.; Fan, R.; Shen, L.; Miller, W. Recycling decisions of low-carbon e-commerce closed-loop supply chain under government subsidy mechanism and altruistic preference. J. Clean. Prod. 2020, 259, 120883. [CrossRef]

61. Samuel, C.N.; Venkatadri, U.; Diallo, C.; Khatab, A. Robust closed-loop supply chain design with presorting, return quality and carbon emission considerations. J. Clean. Prod. 2020, 247, 119086. [CrossRef] 
62. Yu, H.; Solvang, W.D.; Sun, X. A Stochastic Closed-Loop Supply Chain Network Optimization Problem Considering Flexible Network Capacity. In International Workshop of Advanced Manufacturing and Automation; Springer: Singapore, 2019; pp. 567-576.

63. Bertsimas, D.; Brown, D.B.; Caramanis, C. Theory and applications of robust optimization. SIAM Rev. 2011, 53, 464-501. [CrossRef]

64. Ben-Tal, A.; El Ghaoui, L.; Nemirovski, A. Robust Optimization; Princeton University Press: Princeton, NJ, USA, 2009.

65. Peng, H.; Shen, N.; Liao, H.; Xue, H.; Wang, Q. Uncertainty factors, methods, and solutions of closed-loop supply chain-A review for current situation and future prospects. J. Clean. Prod. 2020, 254, 120032. [CrossRef]

66. Govindan, K.; Jafarian, A.; Nourbakhsh, V. Designing a sustainable supply chain network integrated with vehicle routing: A comparison of hybrid swarm intelligence metaheuristics. Comput. Oper. Res. 2019, 110, $220-235$. [CrossRef]

67. Ivanov, D.; Dolgui, A.; Das, A.; Sokolov, B. Digital supply chain twins: Managing the ripple effect, resilience, and disruption risks by data-driven optimization, simulation, and visibility. In Handbook of Ripple Effects in the Supply Chain; Springer: Cham, Switzerland, 2019; pp. 309-332.

Publisher's Note: MDPI stays neutral with regard to jurisdictional claims in published maps and institutional affiliations.

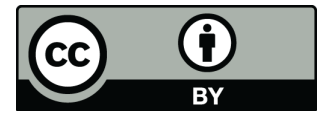

(C) 2020 by the authors. Licensee MDPI, Basel, Switzerland. This article is an open access article distributed under the terms and conditions of the Creative Commons Attribution (CC BY) license (http:/ / creativecommons.org/licenses/by/4.0/). 